\title{
Vasoformative properties of normal and hypoxic retinal tissue
}

\author{
R. D. KISSUN AND A. GARNER \\ From the Department of Pathology, Institute of Ophthalmology, University of London
}

SUMMARY By cannulating the stroma of rabbit corneae, and introducing extracts of retina and vitreous from newborn kittens subjected to vaso-obliterative doses of oxygen, an attempt was made to test the hypothesis that ischaemic retinal tissue releases a factor with vasoformative properties. It was found that, although retino-vitreal extracts from the test animals elicited a positive response in just over half the experiments, the degree of corneal vascularisation provoked by extracts from intact control animals was only marginally less. Consequently our findings do not permit any definite answer regarding the existence of a specific factor responsible for the proliferation of new vessels on the retinal surface in states associated with retinal hypoxia.

Proliferation of blood vessels on the inner surface of the retina can complicate a number of conditions which have in common impaired perfusion of the underlying capillary circulation. Under such circumstances it has been suggested that the retinal tissue in a state of metabolic embarrassment liberates a factor with vasoformative properties able to diffuse into the vitreous and stimulate the growth of new capillaries on the front of the retina (Ashton et al., 1954; Wise, 1956). As yet, however, direct evidence in support of this hypothesis has not been forthcoming.

In this report we describe an attempt to provide more positive evidence of a vasoformative factor in hypoxic retinal tissue using extracts of retinae from kittens which had been subjected to high concentrations of inspired oxygen. Vasoformative activity was sought by observing the effect of the extracts on the limbal blood vessels when introduced into the corneal stroma of healthy rabbits.

\section{Materials and methods}

INDUCTION OF RETINAL NEOVASCULARISATION Five to 12 days after birth litters of kittens were maintained in a continuous atmosphere of $80 \%$ oxygen for 72 hours, by which time there was complete and irreversible obliteration of the retinal vasculature. The kittens were then transferred to normal air and 5 days later were given a lethal intraperitoneal dose of pentobarbitone. In all, 8 kittens were treated in this way. Since a period in

Address for reprints: Dr A. Garner, Department of Pathology, Institute of Ophthalmology, Judd Street, London WC1H 9QS air of about 10 days is required before new channels can be recognised on the retinal surface under these conditions (Ashton et al., 1954) definitive neovascularisation was not seen at the time when the animals were killed.

PREPARATION OF RETINAL EXTRACTS As soon as the kittens were deeply anaesthetised the eyes were enucleated and opened through the ora serrata to allow removal of the retinae. Pooled retinae were homogenised in $0.25 \mathrm{ml}$ distilled water per retina in a motor-driven Teflon homogeniser at $1500 \mathrm{rpm}$ for 1 minute with a pestle clearance of $0.15 \mathrm{~mm}$. The homogenates were then centrifuged at $100000 \mathrm{~g}$ for 1 hour at $4^{\circ} \mathrm{C}$, and the supernates were collected and lyophilised. Extracts were prepared from 8 oxygen-treated and 5 normal control kittens of comparable age.

\section{CORNEAL INTUBATION}

Initially the extracts were dissolved in distilled water at a concentration equivalent to 1 retina or vitreous per $20 \mu l$ and drawn up into nylon tubes to give an equivalent of one extracted retina in each. The tubes were then sealed at one end, the other having been pulled out before filling to provide a very fine structure $(0.6 \mathrm{~mm}$ external diameter) capable of being inserted between the lamellae of the corneal stroma of rabbit eyes. The catheters so formed were inserted into the corneae by a method similar to that introduced by Zauberman et al. (1969). This involved creating a track for subsequent passage of the catheter by introducing an iris repositor, moulded to the curvature of the cornea, through a small incision in the limbal sclera and advancing it to 


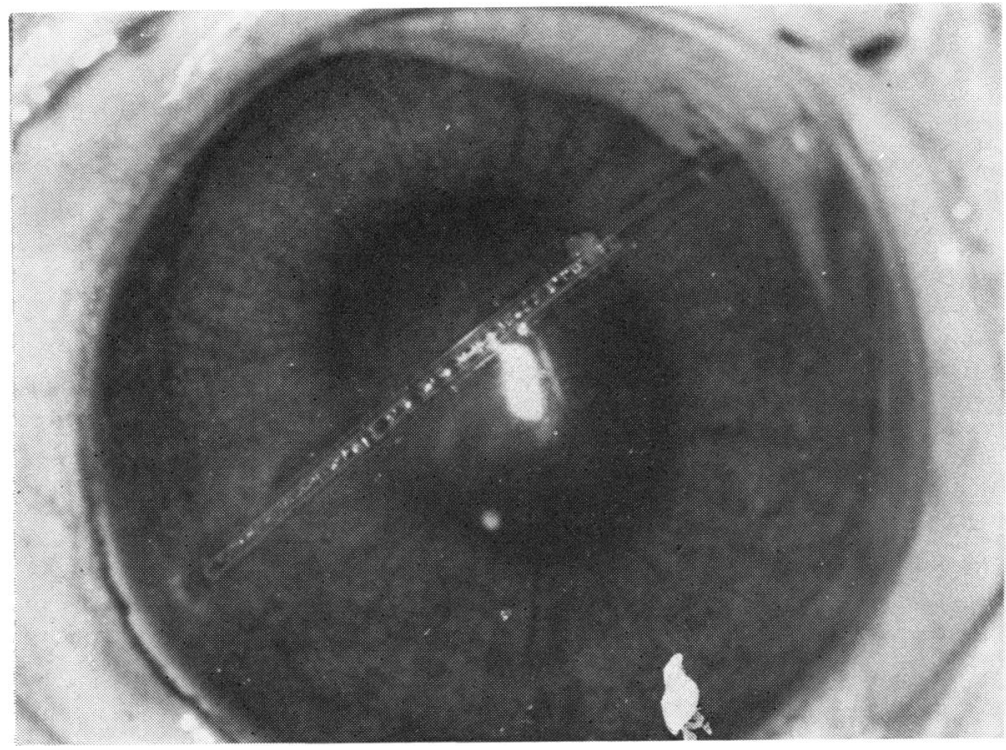

Fig. 1 An enucleated eye showing a fine nylon catheter introduced between the stromal lamellae of the cornea via the perilimbal sclera to within $3 \mathrm{~mm}$ of the limbus on the opposite side. $\times 7$

within 2 to $3 \mathrm{~mm}$ of the opposite limbus (Fig. 1). The wider part of the tube, which acted as a reservoir for the extract, was passed round the circumcorneal region of the globe under the extraocular muscle insertions and held in place with silk sutures. Eleven tubes containing extracts from hyperoxygenated kittens and 6 tubes filled with extracts of normal retinae were inserted by this method. Ten identical operations using empty tubes were also performed.

In later experiments the extracts were mixed with a smaller $(5 \mu l)$ amount of distilled water, and much shorter tubes were introduced directly through the central region of the corneal stroma to within $2 \mathrm{~mm}$ of the limbus. Seven tubes containing modified minimum Eagle's tissue culture medium were also inserted by this method.

\section{Results}

A positive response to the presence of the intracorneal catheter and its contents was marked by an

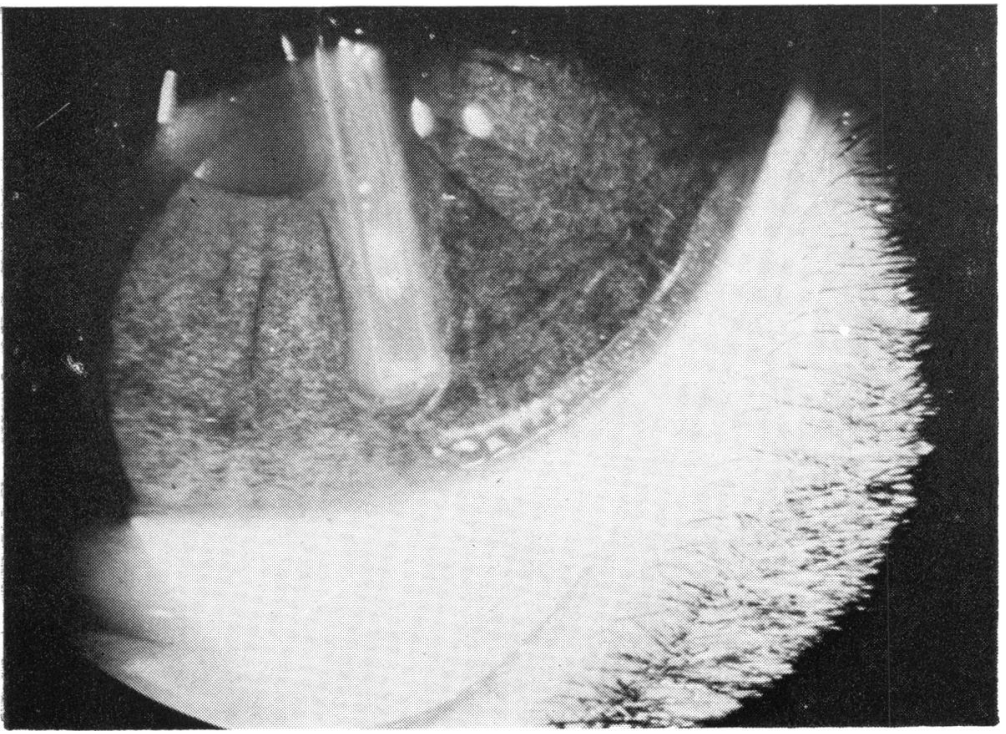

Fig. 2 After insertion there has not been any vasoproliferative activity opposite the open end of an empty (short) tube. The whitish material in the lumen of the tube consisted mainly of macrophages and neutrophil polymorphonuclear leucocytes. $\times 10$ 


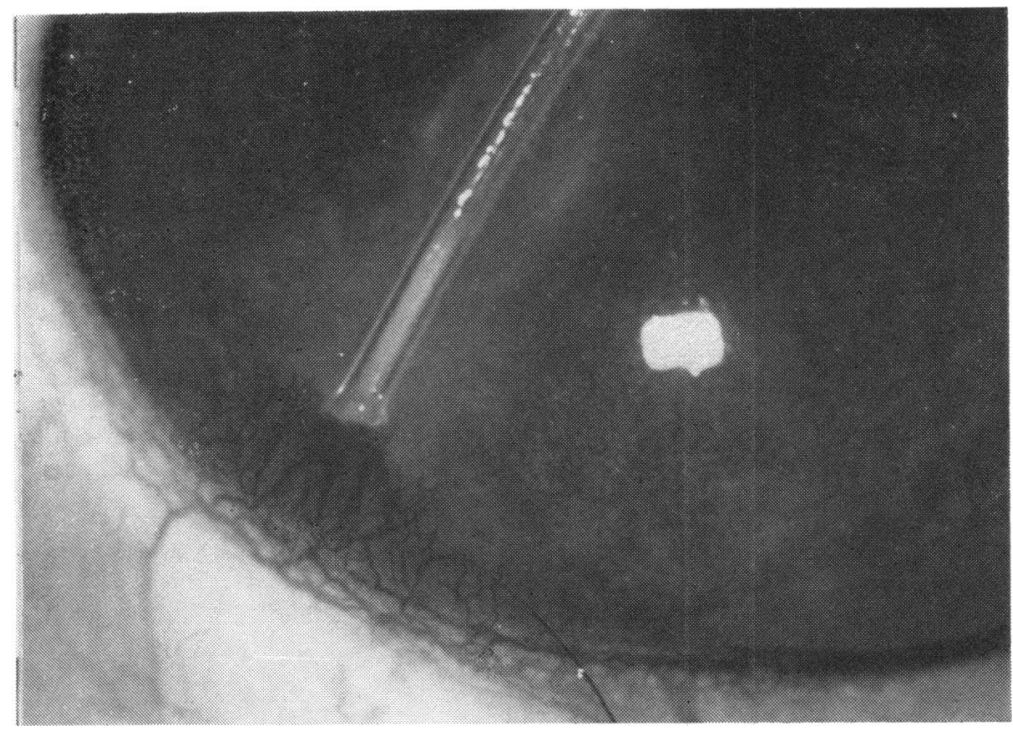

Fig. 3 Intubation with retinal extract from a hyperoxygenated kitten is associated in this instance with vascular infltration of the cornea as far as the orifice of the nylon tube. $\times 10$

initial engorgement and dilatation of the perilimbal vessels of the bulbar conjunctiva. This occurred within the first 2 to 3 days of the intubation and in some instances was the only response. In others the next few days saw a gradual proliferation of recognisable new vessels, which invaded the peripheral cornea opposite the open end of the tube to varying degrees (Figs. 2 and 3 ). In all animals assessment of the vascular response was made on the 10th day, after which the experiments were terminated, since pilot experiments had indicated that if vascularisation was going to occur it would be apparent by such a time. Clinically there was no sign of infection or ulceration in any of the intubated corneae.

Semiquantitative in vivo assessment of the vascular infiltration was attempted and the results are summarised in Table 1. Scoring on an arbitrary scale, we found that the mean vasoproliferative response to hyperoxygenated retinal extracts was $1 \cdot 31$ units; to extracts of normal control retinae the mean response was $1 \cdot 11$ units; whereas the mean response to the presence of an empty tube was 0.36 units. Experiments in which the tubes were filled

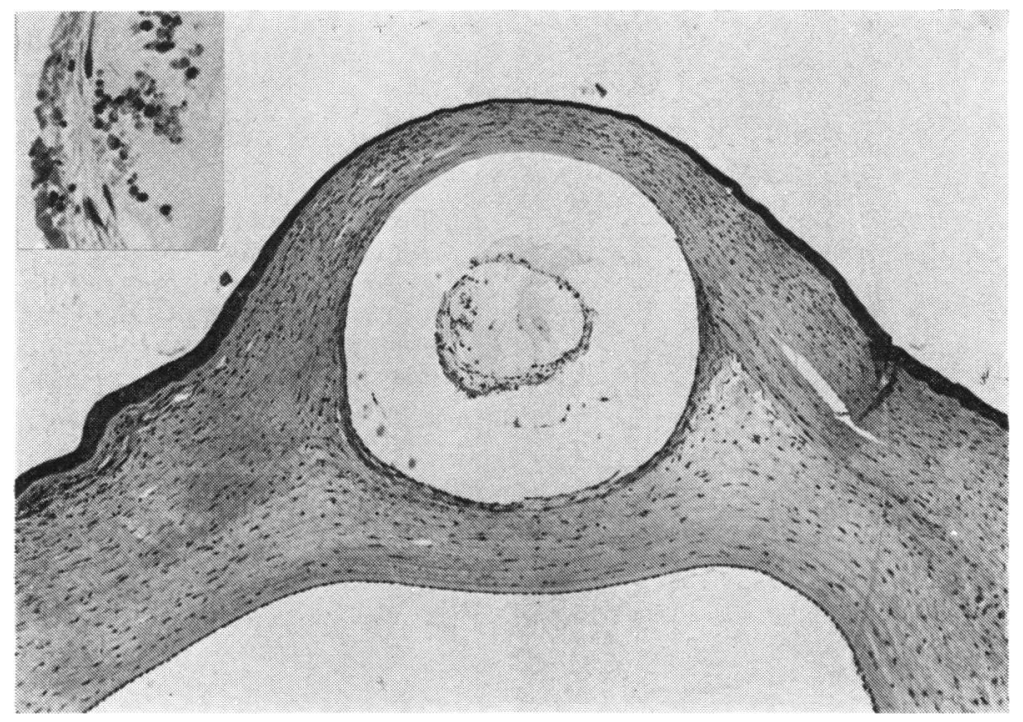

Fig. 4 Section of cornea passing close to the open tip of the tube and showing its position in the mid-stroma. Inset: At higher magnification the cellular infiltrate at the tip of the tube is seen to comprise polymorphs, mononuclear cells, and fibroblasts. $H$ and $E$. $\times 65$ (inset $\times 260$ ) 
Table 1 Degree of corneal vascularisation stimulated by retinal extracts and tissue culture medium in individua. experiments

\begin{tabular}{|c|c|c|c|c|}
\hline Nature of stimulus & $\begin{array}{l}\text { Expt. } \\
\text { no. }\end{array}$ & $\begin{array}{l}\text { Extent of c } \\
\text { vascularisat }\end{array}$ & $\begin{array}{l}\text { corneal } \\
\text { tion }\end{array}$ & $\begin{array}{l}\text { Type of } \\
\text { intracorneal } \\
\text { tube }\end{array}$ \\
\hline \multirow{16}{*}{$\begin{array}{l}\text { Post-hyperoxygenation } \\
\text { retinal extract }\end{array}$} & 1 & $\cdots+-+$ & \multirow{16}{*}{$\begin{array}{l}\text { Mean } \\
\text { score } \\
1 \cdot 31\end{array}$} & Long \\
\hline & 2 & -++ & & ," \\
\hline & 3 & ++ & & , \\
\hline & 4 & - & & , \\
\hline & 5 & $T$ & & , \\
\hline & 6 & $+t+$ & & , \\
\hline & 7 & $\cdots+$ & & , \\
\hline & 8 & - & & , \\
\hline & 9 & - & & , \\
\hline & 10 & - & & \\
\hline & 11 & - & & Short \\
\hline & 12 & -+ & & , \\
\hline & 13 & - & & , \\
\hline & 14 & $+t+$ & & , \\
\hline & 15 & - & & , \\
\hline & 16 & - & & , \\
\hline \multirow{9}{*}{ Normal retinal extract } & 1 & - & \multirow{9}{*}{$\begin{array}{l}\text { Mean } \\
\text { score } \\
1 \cdot 11\end{array}$} & Long \\
\hline & 2 & ++ & & , \\
\hline & 3 & -+ & & , \\
\hline & 4 & - & & ," \\
\hline & 5 & - & & , \\
\hline & 6 & ++++ & & , \\
\hline & 7 & - & & ", \\
\hline & 8 & + & & Short \\
\hline & 9 & - & & , \\
\hline \multirow{14}{*}{ Empty tube } & 1 & - & \multirow{14}{*}{$\begin{array}{l}\text { Mean } \\
\text { score } \\
0.36\end{array}$} & Long \\
\hline & 2 & + & &, \\
\hline & 3 & + & & , \\
\hline & 4 & - & & , \\
\hline & 5 & - & & , \\
\hline & 6 & - & & , \\
\hline & 7 & - & & , \\
\hline & 8 & - & & ", \\
\hline & 9 & - & & ", \\
\hline & 10 & - & & ", \\
\hline & 11 & - & & Short \\
\hline & 12 & - & & , \\
\hline & 13 & +++ & & , \\
\hline & 14 & - & & , \\
\hline \multirow{6}{*}{$\begin{array}{l}\text { Modified Eagle's tissue } \\
\text { culture medium }\end{array}$} & 1 & +++ & \multirow{6}{*}{$\begin{array}{l}\text { Mean } \\
\text { score } \\
2 \cdot 14\end{array}$} & Short \\
\hline & 2 & $++t+$ & & , \\
\hline & 3 & - & & ", \\
\hline & 4 & - & & , \\
\hline & 5 & $++\div$ & & ", \\
\hline & $\begin{array}{l}6 \\
7\end{array}$ & + & & ", \\
\hline
\end{tabular}

Basis of scoring: + Slight engorgement of limbal vessels with minimal $(<1 \mathrm{~mm})$ invasion of cornea by 1 or 2 capillaries

++ More obvious limbal vessel engorgement with larger number of intracorneal capillaries

+++ Corneal vascularisation up to $2 \mathrm{~mm}$

. Vessels impinging on open end of intracorneal tube

with tissue culture medium suitable for growing vascular endothelium in vitro gave a mean vasoproliferative response of $2 \cdot 14$ units.

Vascularisation of the cornea in areas other than opposite the open end of the tube, e.g., in the vicinity of the limbal incision through which the longer tubes were introduced, was discounted for the purposes of the study.
Histological examination of eyes with intracorneal vascular proliferation showed scanty leucocytes, mainly macrophages, but also including very occasional neutrophil polymorphonuclear cells, adjacent to the newly formed vessels. Macrophages were also seen around and within the tip of the implanted tube (Fig. 4), while in experiments in which a short tube was used a little downgrowth of surface epithelium was also seen. In no instance, however, was there any sign of infection or epithelial disturbance in relation to the tip of the tube.

\section{Discussion}

Although the purpose of this series of experiments was to test the hypothesis that hypoxic retinal tissue releases a factor with vasoformative properties, the results fail to provide an unequivocal answer. The response by conjunctival vessels at the corneal limbus to extracts of retina and vitreous from kittens recovering from the vaso-obliterative effects of excessive amounts of oxygen was hardly any better than that engendered by retinal extracts from normal control animals. This finding is open to one or more interpretations.

It is possible that both the normal and the hypoxic retinal extracts acted as non-specific tissue culture media by providing a source of essential metabolites. The experiments in which a modified Eagle's tissue culture medium was implanted in the cornea adequately demonstrated the capacity for this type of vascular growth to occur and showed that the presence of a peculiarly vasoformative factor is not obligatory. Consequently it is possible that the vasoformative potential of retinal tissue extracts is due to the presence of substances with similar nutritive properties. Their presence in healthy retina, albeit at a low concentration, may be necessary to preserve the existing physiological circulation, particularly as it has been found that the vascular proliferation stimulated by vasoformative factor obtained from malignant neoplasms regresses if the factor is withdrawn (Folkman, 1971). Consequently, the difference between normal and ischaemic retinae as regards their vasoformative potentials might be one of degree rather than of kind, the difference being insufficient to be readily detected in our essentially qualitative tests.

It may, however, be necessary to draw a distinction between growth permitted by the provision of a rich source of nutrients, as in tissue extracts, and specific mitogenesis by an agent which is not itself incorporated in the newly formed tissue. For, if the neovascularisation seen in the presence of retinal hypoxia is due to a simple tissue culture effect, it is difficult to account for the lack of similar proliferative 
activity on the part of the adjacent glial cells and the retinal pigment epithelium.

Again, how nutrients comparable to those represented in tissue culture media could be increased in hypoxia is uncertain for, although it has been considered for many years that the products of tissue autolysis, particularly those of nuclear origin (Fischer, 1939), can stimulate vascular proliferation in other organs (Cameron, 1952), retinal neovascularisation is not associated with overt necrosis. On the contrary, it is almost axiomatic that preretinal vessels develop in hypoxic as opposed to anoxic states, and it is difficult to believe that metabolically embarrassed but nevertheless viable retinal tissue would provide a better source of nutrients than would the products of infarction.

Recently Chen and Patz (1976) have shown that the vitreous of newborn puppies contains a soluble protein fraction which disappears over a period of about a month as vascularisation of the retina progresses to completion. Whether the presence of a similar protein in our own control kittens can be invoked to account for the proliferation of vessels at the corneal limbus will depend on whether this moiety is subsequently shown to be causally or only secondarily related to retinal angiogenesis.

Evidence has also been presented indicating the importance of neutrophil polymorphonuclear leucocytes in the pathogenesis of corneal vascularisation, whether as a direct or intermediate factor (Fromer and Klintworth, 1975a, 1975b, 1976), and although leucocytic infiltration of the cornea in the present experiments was not particularly impressive their participation in the vascular response stimulated by retinal tissue cannot be excluded.

It is clear that much work is still to be done if the release of a specific vasoformative factor by retinal tissue is to be demonstrated or refuted. Much of the problem lies in finding a wholly reliable method by which to test any postulated factor, wherein the difficulty in distinguising between peculiarly proliferative stimuli and the mere provision of metabolites essential for endothelial cell growth is excluded. A test in which local factors, such as may well be involved in using the cornea as a substrate (Ashton and Cook, 1953; Cogan, 1962; Fromer and
Klintworth, 1975a), are absent is also desirable. There is also an obvious need to confirm and categorise the protein composition of the vitreous of newborn animals with incompletely vascularised retinae.

We are much indebted to Professor N. Ashton for advice and encouragement in the conduct of this work, to Miss E. Robins for technical assistance, and Mrs A. Wood for secretarial help.

\section{References}

Ashton, N., and Cook, C. (1953). Mechanism of corneal vascularization. British Journal of Ophthalmology, 37, 193-209.

Ashton, N., Ward, B., and Serpell, G. (1954). Effect of oxygen on developing retinal vessels with particular reference to the problem of retrolental fibroplasia. British Journal of Ophthalmology, 38, 397-432.

Cameron, G. R. (1952). Pathology of the cell, p. 448. Oliver \& Boyd: Edinburgh.

Chen, C. H., and Patz, A. (1976). Components of vitreoussoluble proteins: effect of hyperoxia and age. Investigative Ophthalmology, 15, 228-232.

Cogan, D. G. (1962). Corneal vascularization. Investigative Ophthalmology, 1, 253-261.

Fischer, A. (1939). Nature of growth-accelerating substance of animal tissue cells. Nature, 144, 113.

Folkman, J. (1971). Tumour angiogenesis: therapeutic implications. New England Journal of Medicine, 285, 1182-1186.

Fromer, C. H., and Klintworth, G. K. (1975a). An evaluation of the role of leukocytes in the pathogenesis of experimentally induced corneal vascularization. I: Comparison of experimental models of corneal vascularization. American Journal of Pathology, 79, 537-554.

Fromer, C. H., and Klintworth, G. K. (1975b). An evaluation of the role of leukocytes in the pathogenesis of experimentally induced corneal vascularization. II : Studies on the effect of leukocyte elimination on corneal vasculariztion. American Journal of Pathology, 81, 531-544.

Fromer, C. H., and Klintworth, G. K. (1976). An evaluation of the role of leukocytes in the pathogenesis of experimentally induced corneal vascularization. III: Studies related to the vasoproliferative capability of polymorphonuclear leukocytes and lymphocytes. American Journal of Pathology, 82, 157-170.

Wise, G. N. (1956). Retinal neovascularization. Transactions of the American Ophthalmological Society, 54, 729-826.

Zauberman, H., Michaelson, I. C., Bergmann, F., Maurice, D. M. (1969). Stimulation of neovascularization of the cornea by biogenic amines. Experimental Eye Research. 8, 77-83. 